\title{
Thermal - electrical analogy in dynamic simulations of buildings: comparison of four numerical solution methods
}

Piotr MICHALAK

DOI: 10.30464/jmee.2020.4.2.179

Cite this article as:

Michalak P. Thermal - electrical analogy in dynamic simulations of buildings: comparison of four numerical solution methods. Journal of Mechanical and Energy Engineering, Vol. 4(44), No. 2, 2020, pp. 179-188.

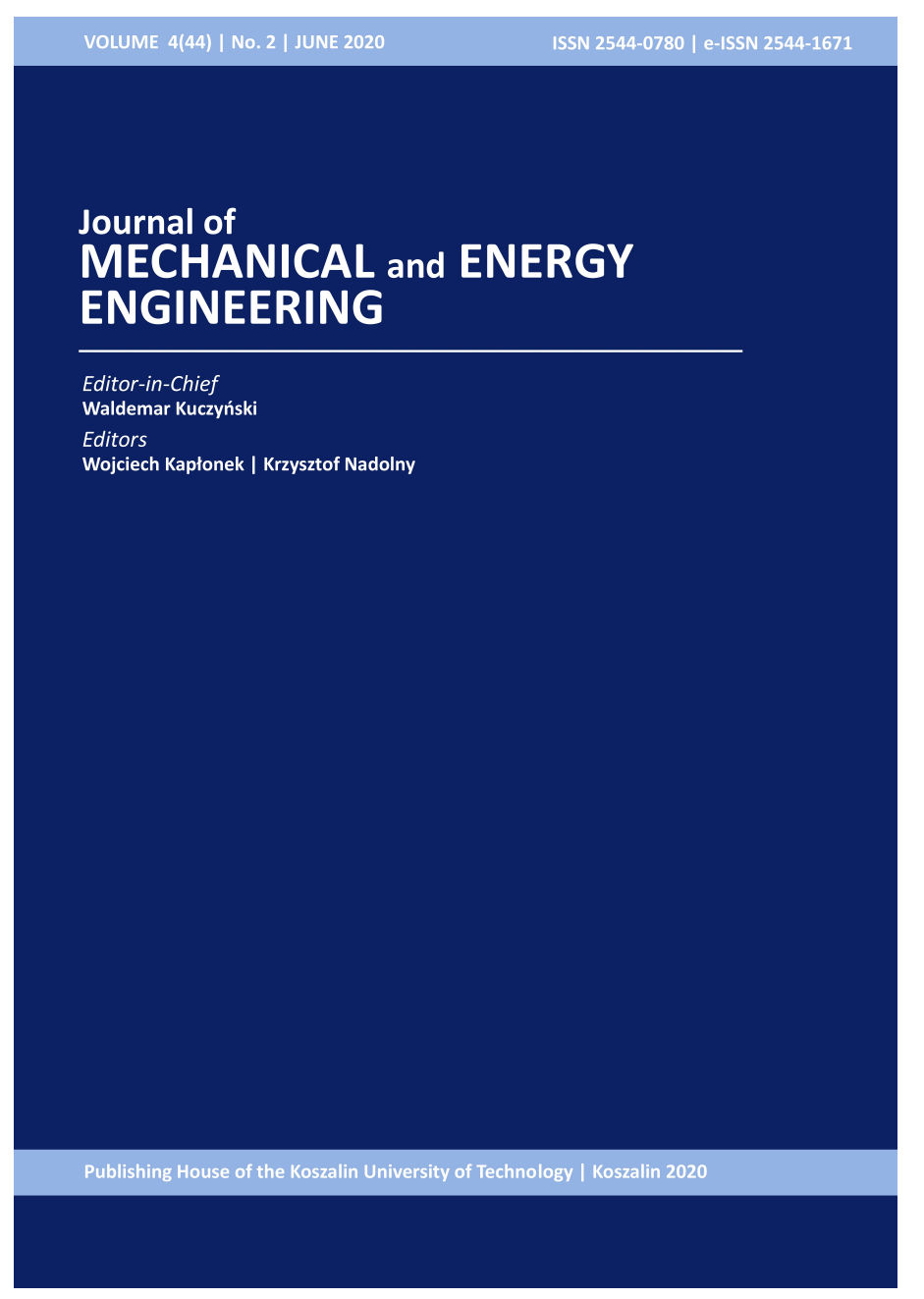

Journal of Mechanical and Energy Engineering

Website: jmee.tu.koszalin.pl

ISSN (Print): 2544-0780

ISSN (Online): 2544-1671

Volume: 4(44)

Number: 2

Year: 2020

Pages: $179-188$

Article Info:

Received 4 June 2020

Accepted 9 July 2020

Open Access

This article is distributed under the terms of the Creative Commons Attribution 4.0 (CC BY 4.0) International License (http://creativecommons.org/licenses/by/4.0/), which permits unrestricted use, distribution, and reproduction in any medium, provided you give appropriate credit to the original author(s) and the source, provide a link to the Creative Commons license, and indicate if changes were made. 


\title{
THERMAL - ELECTRICAL ANALOGY IN DYNAMIC SIMULATIONS OF BUILDINGS: COMPARISON OF FOUR NUMERICAL SOLUTION METHODS
}

\author{
Piotr MICHALAK ${ }^{1 *}$ \\ ${ }^{1 *}$ Faculty of Mechanical Engineering and Robotics, Department of Power Systems and Environmental \\ Protection Facilities, AGH University of Science and Technology, Mickiewicza 30, 30-059 Kraków, Poland, \\ e-mail:pmichal@agh.edu.pl
}

(Received 4 June 2020, Accepted 9 July 2020)

\begin{abstract}
The lumped capacitance method is widely used in dynamic modelling of buildings. Models differ in complexity, solution methods and ability to simulate transient behaviour of described objects. The paper presents a mathematical description of a simple 1R1C thermal network model of a building zone. Four numerical methods were applied to solve differential equation describing its dynamics. For validation purposes two test cases (600 and 900) from the BESTEST procedure were used. In both cases detailed results were given. Better ability of the simulation model to reproduce transient behaviour of the modelled buildings was noticed in case of the lightweight object (case 600). Annual heating and cooling demand was within the reference range for heavyweight one (case 900). The kind of the computation method had no significant effect on simulation results.
\end{abstract}

Keywords: thermal-electrical analogy, RC network, lumped capacitance, BESTEST, Euler method, Heun's method

\section{INTRODUCTION}

Determination of the amount of energy for space heating and cooling is crucial in auditing, certification and thermal modernisation of buildings [1]. For this purpose steady-state, quasi steady-state and dynamic methods [2] can be used. The latter ones enable transient analyses in hourly (or less) time step. They are also commonly applied in numerous simulation tools because of the rapid development of the computer technology. Dynamic methods include weighting factor and heat balance methods [3-5]. The second group contains response factor method, conduction transfer functions, finite difference method and lumped capacitance method [6-7].

Because of its simplicity and low computational demand the lumped capacitance method was commonly applied in researches [8-13] and standards, as VDI 6007 [14-15] or PN-EN ISO 13790 [16]. It is based on the thermal-electrical analogy [17-18]. In this approach the voltage source corresponds to the temperature, current - heat flux, resistor - thermal resistance and capacitor - thermal capacity. From this a dynamic model of a building in the form of an electrical scheme can be built. From the circuit theory there can be written nodal equations for each node of that network [19]. These are differential equations for nodes with connected capacitor (dynamic element) or algebraic equations for non-capacitive nodes.

As analytical solutions are usually difficult to obtain, numerical methods are applied in computer simulation tools. It should be done carefully, because there is a risk of instabilities between subsequent calculation time steps because of the non-continuous nature of boundary conditions given by weather, occupants or HVAC systems. Also significant changes in input values (outdoor temperature, ventilation rate, etc.) may occur between subsequent time steps [20-23]. These factors influence calculated instantaneous indoor temperature and thermal power required to maintain set point temperature. Thus, accurate modelling of transient states is important from the point of view of design procedures.

This paper presents a simple RC lumped capacitance model of a building zone, under varying 
external and internal conditions, solved by four numerical methods. They were applied in a typical spreadsheet, not requiring specialized software.

Selected waveforms of the indoor temperature were shown and peak heating and cooling power and annual energy for space heating and cooling were calculated. Obtained results were discussed and finally concluding remarks were given.

\section{RC MODEL OF A BUILDING ZONE}

\subsection{Introduction}

As aforementioned, a number of different schemes of RC networks have been presented in literature. To avoid complicated mathematical description a simple model with a single capacitor seemed to be a reasonable solution. It has been found that a number of researchers has presented such models in the last decades obtaining satisfactory accuracy [24-38]. Therefore, a single node 1R1C model (one capacitor and one resistor) thermal network model of a building zone (Fig. 1) has been chosen. Obviously, this model makes it impossible to accurately account for a number of phenomena, but in spite of that it was applied in several studies [39-43] which confirmed its practical usability in different cases.

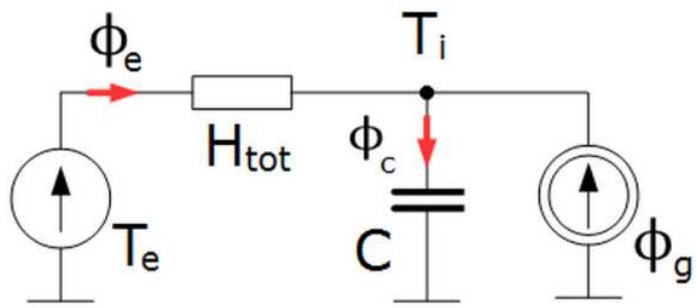

Fig. 1. The 1R1C thermal network model of a building

The total heat transfer between the external and internal environment includes thermal transmittance through external partitions (walls, windows, roof and by floor to the ground) and by ventilation:

$$
H_{t o t}=H_{t r}+H_{v e} \text {. }
$$

The heat flux $\phi_{g}$ includes solar gains, internal gains and thermal power (heating or cooling) delivered directly to the internal air:

$$
\phi_{g}=\phi_{\text {sol }}+\phi_{\text {int }}+\phi_{H C} .
$$

The single capacitor includes the thermal capacity of the considered building.

\subsection{Mathematical description}

Assuming directions of heat fluxes presented in Fig. 1, from the Kirchhoff's Current Law (KCL) for the node $T_{i}$, it can be written that:

$$
\phi_{c}=\phi_{e}+\phi_{g},
$$

where:

$$
\phi_{e}=H_{t o t}\left(T_{e}-T_{i}\right) \text {, }
$$

and:

$$
\phi_{c}=C \frac{d T_{i}}{d t}
$$

Inserting Eqs. (4) and (5) into (3) yields:

$$
C \frac{d T_{i}}{d t}=H_{t o t}\left(T_{e}-T_{i}\right)+\phi_{g},
$$

and finally:

$$
\frac{d T_{i}}{d t}=\frac{H_{t o t}}{C}\left(T_{e}-T_{i}\right)+\frac{\phi_{g}}{C} .
$$

Eq. (7) is a first order ordinary differential equation in the general form of:

$$
\frac{d y(t)}{d t}=f(t, y(t))
$$

with the initial condition:

$$
y\left(t_{0}\right)=y_{0} .
$$

Assuming $\phi_{g}=0$ and $T_{i}(0)=0$ Eq. (7) can be easily solved analytically [19]:

$$
T_{i}(t)=T_{e} \cdot\left(1-e^{-t \cdot H_{t o t} / C}\right),
$$

The expression:

$$
\tau=H_{t o t} / C=R_{t o t} \cdot C,
$$

is called the thermal time constant and indicates a time required for a given body (wall, floor, whole building, etc.) to respond to a change in its ambient temperature.

\section{TIME COUNTING IN SIMULATIONS}

\subsection{Introduction}

Dynamic simulations of buildings are typically performed in hourly, or sub-hourly, time steps for the whole year. Boundary conditions, given by weather data, occupancy and control schedules are given in the same time resolution. Within that period, at consecutive time steps, all required boundary conditions are known and then differential equations are solved. Then output results are used to obtain solution at the next time step and so on until the end time is reached.

In order to clearly determine the current moment at which calculations are carried out, the convention for counting the simulation time should be established.

\subsection{ISO 8601 standard}

The ISO 8601 standard [44] recommends the use of time scales applying the 24-hour time keeping 
system for the identification of time points within a calendar day.

Hour is represented by two digits from 00 to 24 . But the value of 24 is allowed only to indicate the end of a calendar day within a time interval. Minute is represented by two digits from 00 to 59 . Second is represented by two digits from 00 to 60 , but the value of 60 is allowed only to indicate a positive leap second or an instant within that second.

Beginning and end of day is represented by 00:00:00 and 24:00:00, respectively. But the end of one calendar day 24:00 coincides with 00:00 at the start of the next calendar day. Thus, the time 24:00 on 2 January is the same as 00:00 on 3 January. Hence, this method of time representation should be used in computer simulation programs with caution.

\subsection{Simulation tools}

Application of abovementioned recommendations to computer codes requires caution so as not to cause errors during transitions between successive hours.

Usually the default time step in simulation tools to calculate buildings thermal loads is one hour regardless of the fact that sub-hourly values are also possible. It is so, because weather data files are in hourly formats [45-47].

For example, in DOE-2, EnergyPlus and Helios programs a day is from hour 1 to hour 24. Hour 1 means the time interval from 00:00:01 to 1:00:00 (see Fig. 2). In DeST a day is from hour 0 to hour 23. Hour 0 represents the time interval from 00:00:00 to 00:59:59 [48-49].

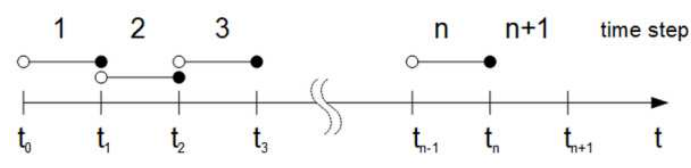

Fig. 2. Time counting in simulations

The first convention was adopted in the paper. Omitting seconds for convenience it means that hour 1 covers the time interval from 00:01 to 01:00.

\section{NUMERICAL SOLUTIONS}

\subsection{Introduction}

To solve Eq. (7) finite difference methods can be applied. They use and approximation of the derivative from that equation by the arithmetic difference: forward, backward or central [50-51].

Computational methods using aforementioned schemes differ in accuracy, stability and complexity of solution algorithms. Four of them are presented in the following section, namely forward Euler, backward Euler, trapezoid and Heun's (improved Euler) [52-56].

\subsection{Forward Euler}

Forward Euler method (explicit) uses forward difference approximation at the $\mathrm{n}$-th time step:

$$
y^{\prime}\left(t_{n}\right)=\frac{d y\left(t_{n}\right)}{d t} \approx \frac{y_{n+1}-y_{n}}{t_{n+1}-t_{n}} .
$$

Typically the length of the time step is assumed to be constant for the whole simulation period:

$$
t_{n+1}-t_{n}=\Delta t
$$

and this condition is followed in the paper. Hence, the general scheme of this method can be written as:

$$
\frac{y_{n+1}-y_{n}}{\Delta t}=f\left(t_{n}, y_{n}\right) .
$$

Rearranging Eq. 14 we obtain:

$$
y_{n+1}=y_{n}+\Delta t \cdot f\left(t_{n}, y_{n}\right) \text {. }
$$

Looking at Eq. (15) it can be easily noticed that in an explicit formula the right side of that equation has only known variables. Taking the internal temperature $T_{i}$ as the unknown variable y and applying Eq. (15) into Eq. (6) we get for the n-th calculation time step:

$$
\frac{T_{i, n+1}-T_{i, n}}{\Delta t}=\frac{H_{t o t, n}}{C}\left(T_{e, n}-T_{i, n}\right)+\frac{\phi_{g, n}}{C} .
$$

The thermal capacity was assumed to be constant and therefore it wasn't assigned with the subscript " $n$ ".

From Eq. (16) the unknown internal temperature at the $n+1$ time step can be derived on the base of the value from the previous moment:

$$
T_{i, n+1}=\left(1-\frac{H_{t o t, n}}{C} \Delta t\right) T_{i, n}+\frac{H_{t o t, n} \cdot T_{e, n}+\phi_{g, n}}{C} \Delta t .
$$

This method is very easy to apply in computing procedures. Its disadvantage is the instability, which can be eliminated by the suitable choice of time step.

To obtain stability condition Eq. (8) should be rewritten in the form:

$$
\frac{d y(t)}{d t}=\lambda \cdot y(t)
$$

Solution of Eqn. (18) is stable if:

$$
|1+\lambda \cdot \Delta t|<1
$$

Comparing Eq. (19) with Eq. (7) it can be easily noticed that:

$$
\lambda=-\mathrm{H}_{\mathrm{tot}} / \mathrm{C},
$$

and:

$$
\left|1-\frac{H_{t o t}}{C} \cdot \Delta t\right|<1 .
$$




\subsection{Backward Euler}

Backward Euler method (implicit) uses backward difference approximation. It is similar to Eq. (12) but evaluates the function $f(t, y)$ at the future time step:

$$
y^{\prime}\left(t_{n+1}\right)=\frac{d y\left(t_{n+1}\right)}{d t} \approx \frac{y_{n+1}-y_{n}}{t_{n+1}-t_{n}} .
$$

Consequently, following the previous section, the general solution scheme for this method has the form:

$$
y_{n+1}=y_{n}+\Delta t \cdot f\left(t_{n+1}, y_{n+1}\right) \text {. }
$$

The unknown value $\mathrm{y}_{\mathrm{n}+1}$ appears on both sides of the Eq. (23). Applying Eq. (23) to Eq. (7) we obtain:

$$
T_{i, n+1}=\frac{T_{i, n}+\frac{H_{t o t, n+1} \cdot T_{e, n+1}+\phi_{g, n+1}}{C} \Delta t}{1+\frac{H_{t o t, n+1}}{C} \Delta t} .
$$

This method is computationally more expensive per time step than the forward method, but it is numerically more stable. form:

In this case stability condition for Eq. (18) has the

$$
\left|\frac{1}{1-\lambda \cdot \Delta t}\right|<1 .
$$

\subsection{Trapezoid method}

This method is similar to the previous one, but more accurate and fast. For $\lambda<0$ it is absolutely stable. In general form applied to multiple dimensional partial differential equations it is known as the CrankNicholson method. It uses the approximation of the derivative at the midpoint by the expression:

$$
y_{n+1 / 2}=y\left(\frac{t_{n}+t_{n+1}}{2}\right) \approx \frac{y_{n}+y_{n+1}}{2}
$$

The general solution scheme for this method has the following form:

$$
y_{n+1}=y_{n}+\frac{\Delta t}{2} \cdot\left(f\left(t_{n}, y_{n}\right)+f\left(t_{n+1}, y_{n+1}\right)\right) .
$$

The method is implicit because the unknown $\mathrm{y}_{\mathrm{n}+1}$ appears on both sides of the Eq. (27).

Applying Eqs. (7) and (8) into (27) we obtain:

$$
\begin{gathered}
T_{i, n+1}=\frac{T_{i, n}+\frac{H_{t o t, n} \cdot T_{e, n}+\varphi_{g, n}}{2 C} \Delta t}{1+\frac{H_{t o t, n+1}}{2 C} \Delta t}+ \\
+\frac{\frac{H_{t o t, n+1} \cdot T_{e, n+1}+\varphi_{g, n+1}}{2 C} \Delta t}{1+\frac{H_{t o t, n+1}}{2 C} \Delta t} .
\end{gathered}
$$

\subsection{Heun's method}

This method is also known as improved Euler method. Instead of the derivative value calculated at the beginning of the interval, as it was in the Euler method, the derivative is also calculated at the end of the interval. The first result is called a predictor:

$$
k_{1}=\Delta t \cdot f\left(t_{n}, y_{n}\right)
$$

and a corrector:

$$
k_{2}=\Delta t \cdot f\left(t_{n+1}, y_{n}+k_{1}\right) .
$$

Then:

$$
y_{n+1}=y_{n}+\Delta t \cdot \frac{1}{2}\left(k_{1}+k_{2}\right) .
$$

Heun's method uses forward Euler's method as predictor and trapezoid method as corrector. Thanks to the introduced modification this method is more accurate than the classic Euler method.

Applying Eq. (7) and (8) into Eq. (29) we obtain:

$$
k_{1}=\frac{H_{t o t, n} \cdot\left(T_{e, n}-T_{i, n}\right)+\phi_{g, n}}{C} \Delta t .
$$

Then, the same are inserted into (25) giving:

$$
k_{2}=\frac{H_{t o t, n} \cdot\left(T_{e, n}-T_{i, n}-k_{1}\right)+\phi_{g, n}}{C} \Delta t .
$$

Having given $\mathrm{k}_{1}$ and $\mathrm{k}_{2}$ variables they are inserted into Eq. (31) and the resulting temperature is obtained.

Stability condition for this method is described by the equation:

$$
\left|1-\lambda \cdot \Delta t+\frac{1}{2}(\lambda \cdot \Delta t)^{2}\right|<1
$$

\section{SIMULATIONS}

\subsection{BESTEST procedure}

To show an application of the aforementioned methods in thermal computations an exemplary test building from the BESTEST procedure [57] was used.

It was developed by the National Renewable Energy Laboratory in collaboration with the International Energy Agency.

It is a validation method based on comparative testing of building simulation programs including several test cases evaluating the influence of different physical processes on the simulation results. The basis for comparison is a range of results from a number of reference programs, such as EnergyPlus, BLAST, DOE2, COMFIE, ESP-r and others. A number of test cases of BESTEST have been incorporated into ANSI/ASHRAE Standard 140 [58].

\subsection{Test cases}

The BESTEST method covers a number of different tests to check buildings and their systems. To compare calculation algorithms shown in Section 4 there were chosen cases 600 and 900 , i.e. base tests for low and heavy mass building, respectively. 
In these tests the ANSI 140 standard uses an exemplary test building (Fig. 3) [59-63]. It also describes the thermal and physical properties of building elements, windows properties, schedules of internal gains, ventilation and thermostat control and heat transfer coefficients for all tests. The model of the outdoor climate is given in the form of 8760 hourly values of climatic data for Denver in the USA $\left(39.8^{\circ}\right.$ $\mathrm{N}, 104.9^{\circ} \mathrm{W}, 1609 \mathrm{~m}$ above sea level).

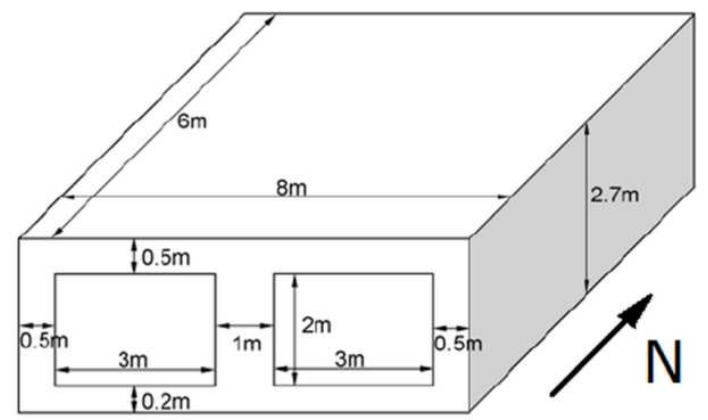

Fig. 3. The test building for cases 600 and 900

In the test 600 the building is of lightweight construction. Constant infiltration of 0.5 air change per hour is assumed. Internal load: $200 \mathrm{~W}$ continuous, $60 \%$ radiative, $40 \%$ convective, $100 \%$ sensible. It uses mechanical heating and cooling air system, 100\% convective, $100 \%$ efficient, with no duct losses and no capacity limitation and no latent heat extraction. Temperature is controlled by non-proportional-type dual set-point thermostat with deadband. Internal setpoint temperatures: $T_{i, H, \text { set }}=20^{\circ} \mathrm{C}$ and $T_{i, C, \text { set }}=27^{\circ} \mathrm{C}$. The test 900 uses the same building model as previously, except heavier materials used for construction of the wall and floor. Everything else with the building remained the same.

From the abovementioned data there were calculated values (Tab. 1) of elements of the RC model of the building (Fig. 1). The thermal capacitance was obtained according to the detailed method of ISO 13786 for the calculation period of 24 hours [64].

Tab. 1. Values of the RC model

\begin{tabular}{llr}
\hline Test case & $H_{\text {tot }}[\mathrm{W} / \mathrm{K}]$ & \multicolumn{1}{c}{$C[\mathrm{~kJ} / \mathrm{K}]$} \\
\hline 600 & 104.300 & 1966.68 \\
\hline 900 & 104.165 & 12545.74
\end{tabular}

The procedure to calculate hourly heating/cooling power $\phi_{H C, n d, a c}$ to maintain the required indoor air temperature (Fig. 4) was taken from [16].

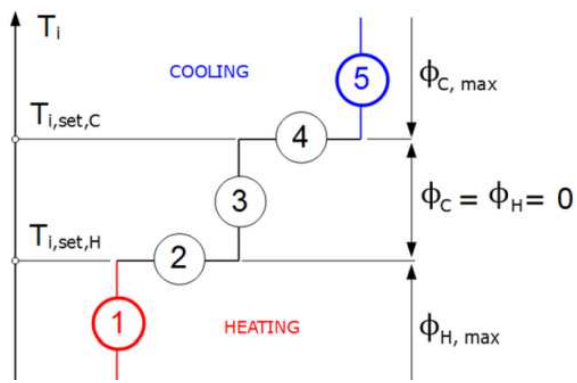

Fig. 4. Control strategy to maintain a required internal air temperature

Firstly, the calculation method (see section 4) to obtain internal temperature is chosen. Next, it is checked if heating or cooling is required (case 3 from Fig. 4). For $\phi_{H C}=0$ internal temperature is calculated. The resulting $T_{i}$ is named as $T_{i, 0}$. If $T_{i, s e t, H} \leq T_{i, 0} \leq$ $T_{i, s e t, C}$, no heating or cooling is required, so $\phi_{H C}=0$ and $T_{i}=T_{i, 0}$ and no further calculations are needed. If not, next step is applied. If $T_{i, 0}>T_{i, \text { set, } C}$ take $T_{i, \text { set }}=$ $T_{i, s e t, C}$, else (if $T_{i, 0}<T_{i, s e t, H}$ ) take $T_{i, \text { set }}=T_{i, s e t, H}$. Then calculate $\phi_{H C}=\phi_{H C, n d, 10}$, where:

$$
\phi_{H C, n d, 10}=10 A_{f} .
$$

For this value $T_{i}$ is computed again, the resulting value is named as $T_{i, 10}$ and then unrestricted heating or cooling power is calculated from the equation:

$$
\phi_{H C, n d, u n}=\phi_{H C, n d, 10}\left(T_{i, s e t}-T_{i, 0}\right) /\left(T_{i, 10}-T_{i, 0}\right) .
$$

Now it is checked whether available cooling or heating power is sufficient (case 2 or case 4). If $\phi_{C, \max }$ $<\phi_{H C, \text { nd, un }}<\phi_{H, \max }$, then $\phi_{H C}=\phi_{H C, n d, \text { un }}, T_{i}=T_{i, \text { set }}$ and the calculation is completed. If this condition is not satisfied, then (case 1 or case 5) the internal temperature is calculated for $\phi_{H C, n d, u n}=\phi_{H, \max }$, when $\phi_{H C, n d, u n}>0$ or $\phi_{H C, n d, u n}=\phi_{C, \max }$, when $=\phi_{H C, n d, u n}<0$. In this case the set point temperature is not reached and calculations for the current time-step end.

\section{RESULTS AND DISCUSSION}

\subsection{Introduction}

Calculations were performed in two ways. In the first one the analytical solution given by Eq. (10) was considered.

In the second part calculation models, described in the section 4, were applied in a spreadsheet along with the internal air temperature control strategy. Solar heat gains were determined according to [16]. Hourly solar irradiance incident on vertical surfaces was computed applying the Perez model [65].

In the next sections numerical methods were assigned as follows: forward Euler (1), backward Euler (2), trapezoid (3) and Heun's (4). 


\subsection{Analytical solution}

To compare accuracy of the presented methods with analytical solution given by Eq. (10) the test building from Fig. 3 was used. Assuming values of $H_{\text {tot }}$ and $C$ from Table 1 and external air temperature step change of $\Delta T_{e}=50 \mathrm{~K}$ variation of internal air temperature was calculated using presented numerical methods. Results for test case 600 and 900 are shown in Fig. 5 and Fig. 6, respectively.

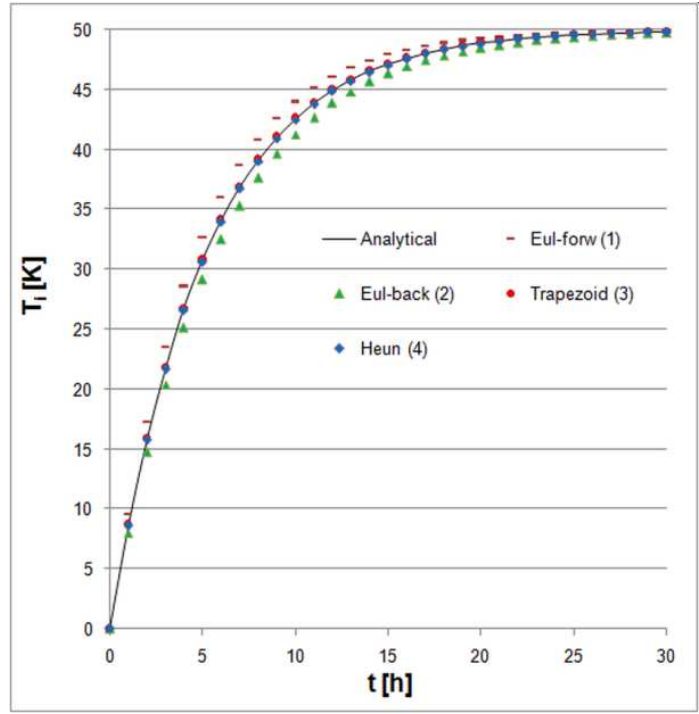

Fig. 5. Internal air temperature change in the case 600

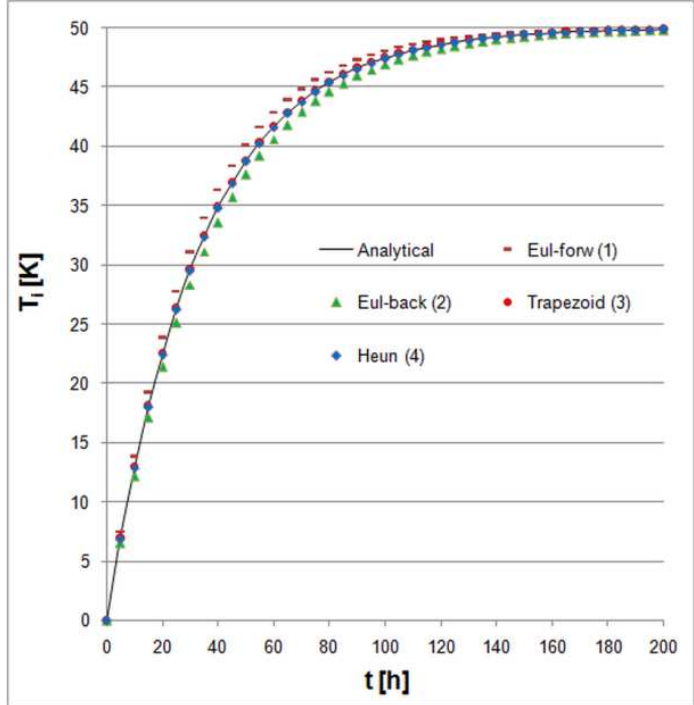

Fig. 6. Internal air temperature change in the case 900

In both cases $T_{i}$ waveforms are the same. They differ only in time scale resulting from the thermal time constants of both buildings.

All methods provided good fitting of the calculated values with the analytical solution. But it was rather simple example. In case of varying conditions the situation is more complicated.

\subsection{BESTEST tests}

Table 2 shows minimum and maximum reference values of annual heating and cooling energy and peak power from BESTEST and calculation results for all methods in the case 600 .

Heating demand and peak cooling power were underestimated in all methods and amounted from $3751 \mathrm{kWh}$ (3-rd method) to $4028 \mathrm{kWh}$ (1) and from $4241 \mathrm{~W}$ (2) to $4710 \mathrm{~W}$ (1), respectively. So, their discrepancy was relatively small comparing to the computed average values.

Annual cooling energy was within the required range only in forward Euler method. Peak heating power was calculated properly by all methods.

Tab. 2. Case 600 tests results

\begin{tabular}{|c|c|c|c|c|c|}
\hline Min & Max & 1 & 2 & 3 & 4 \\
\hline \multicolumn{6}{|c|}{ Annual heating, kWh } \\
\hline 4296 & 5709 & 4028 & 3574 & 3751 & 3764 \\
\hline \multicolumn{6}{|c|}{ Annual cooling, $\mathrm{kWh}$} \\
\hline 6137 & 7964 & 6426 & 5836 & 6070 & 6084 \\
\hline \multicolumn{6}{|c|}{ Peak heating, W } \\
\hline 3437 & 4354 & 4222 & 4112 & 4140 & 4162 \\
\hline \multicolumn{6}{|c|}{ Peak cooling, W } \\
\hline 5965 & 6827 & 4710 & 4241 & 4394 & 4440 \\
\hline
\end{tabular}

Tests for annual heating and cooling in all methods were passed for simulations of the thermally heavy building in case 900 . Peak heating and cooling power was underestimated in all methods.

Tab. 3. Case 900 tests results

\begin{tabular}{|c|c|c|c|c|c|}
\hline Min & $\operatorname{Max}$ & 1 & 2 & 3 & 4 \\
\hline \multicolumn{6}{|c|}{ Annual heating, kWh } \\
\hline 1170 & 2041 & 1220 & 1202 & 1208 & 1210 \\
\hline \multicolumn{6}{|c|}{ Annual cooling, $\mathrm{kWh}$} \\
\hline 2132 & 3415 & 2930 & 2913 & 2918 & 2921 \\
\hline \multicolumn{6}{|c|}{ Peak heating, W } \\
\hline 2850 & 3797 & 2687 & 2650 & 2654 & 2668 \\
\hline \multicolumn{6}{|c|}{ Peak cooling, W } \\
\hline 2888 & 3871 & 1888 & 1872 & 1878 & 1880 \\
\hline
\end{tabular}

Based on the results presented in Table 2 and Table 3 the usefulness of the analysed calculation models for energy assessment of buildings can be determined. But to evaluate their ability to simulate transient states a deeper analysis is needed. It can be performed on the base of the more detailed charts shown in Fig. 7 and Fig. 8.

Regardless of the type of a building all methods reproduced the hourly heating and cooling load in the 
same way. The shape and variability of presented waveforms is the same. Maximum and minimum hourly values of thermal power differed from $116 \mathrm{~W}$ (7-th hour) to $1466 \mathrm{~W}$ (11) and from $45 \mathrm{~W}$ (17) to 223 $\mathrm{W}(12)$ in the case 600 and 900 , respectively.

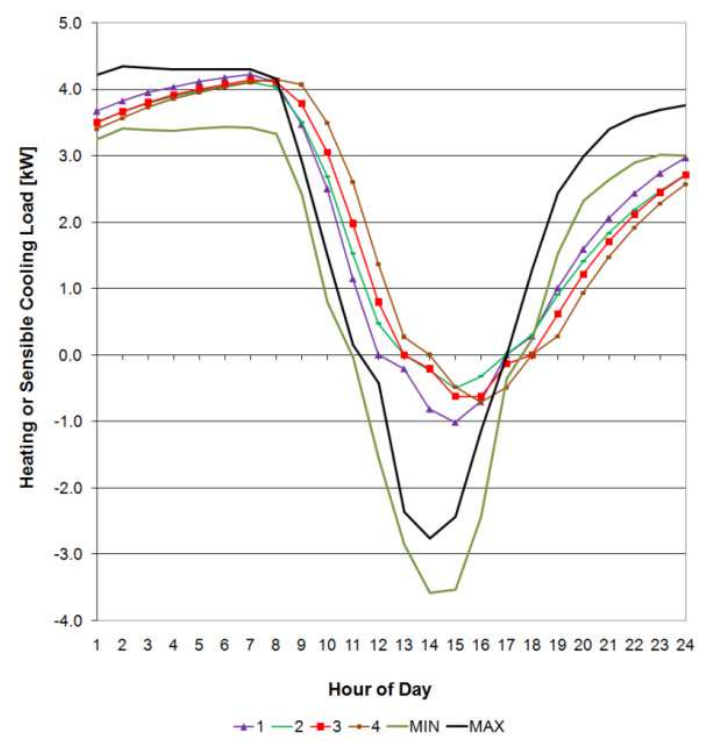

Fig. 7. Thermal power on 4-th January in the case 600

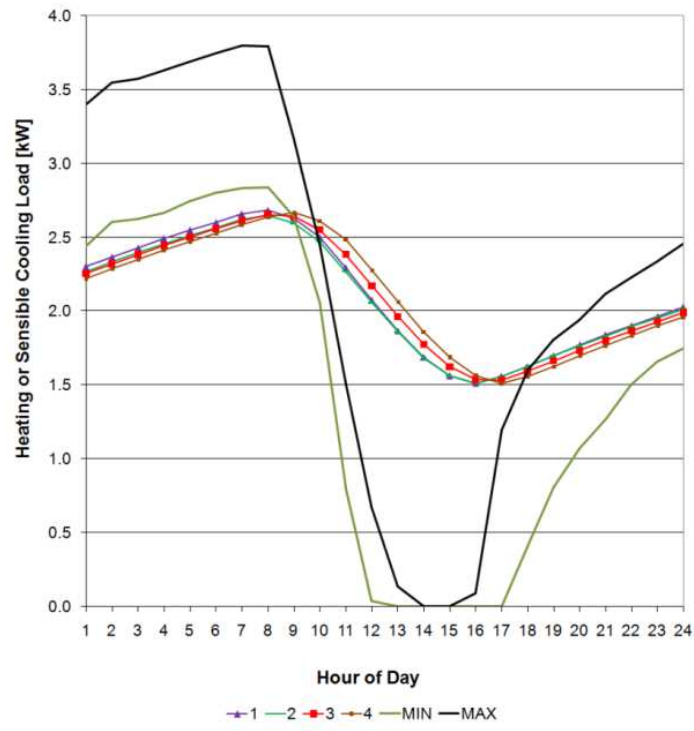

Fig. 8. Thermal power on 4-th January in the case 900

Lower discrepancies between individual methods occurred for the heavy building case. Smaller differences, in relation to the reference values, were noticed for a light building.

Better compliance of computed hourly power values with the reference range was visible during low variability of the external conditions (hours 1-7 and 20-24) not influencing thermal balance of the building.
To illustrate this problem global solar irradiance $\left(I_{s o l}\right)$ and external air temperature $\left(T_{e}\right)$ during 4-th January were shown in Fig. 9. Significant and rapid change in solar gains and external air temperature caused a decrease in the demand for heating power within a short period of time.

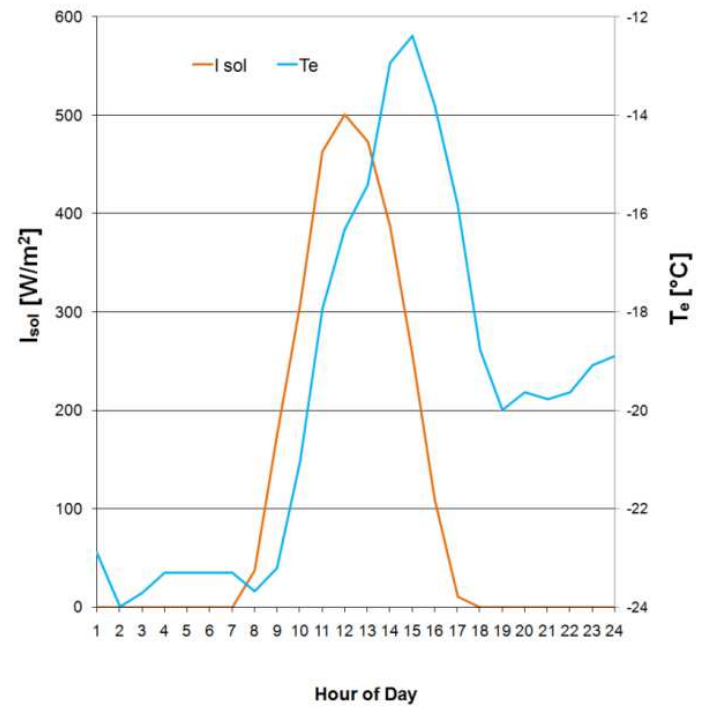

Fig. 9. Global horizontal solar irradiance and external air temperature on 4-th January

Smaller discrepancies were noticed in case of the thermally light object, which react faster to changes in external and internal conditions.

Differences between presented methods and reference waveforms are caused by the simplicity of the RC model. In this model solar irradiance incident on the external walls, calculated using the method from [16], is included on the internal side of a zone.

\section{CONCLUSIONS}

The lumped capacitance 1R1C thermal network model of a building zone was presented and numerically solved by four methods. In spite of its simplicity the model showed abilities to simulate thermal dynamics of simple buildings.

Presented simulations confirmed that numerical methods selected to solve presented problem affected final results depending on the type of the building. But literature review has revealed that not only calculation method, but the layout and physical background of the thermal network is very important, as well. It was confirmed by numerous experiences associated with the use of more complex models with one capacitor [66-70] indicating that its modification may result in better calculation accuracy while maintaining its simplicity and low computational demand. 


\section{Nomenclature}

Symbols

$t \quad-$ time, $\mathrm{s}$

C $\quad-$ thermal capacity, $\mathrm{J} / \mathrm{K}$

$H_{\text {tot }} \quad$ - total heat transfer between the external and internal environment, $\mathrm{W} / \mathrm{K}$

$H_{t r} \quad$ - thermal transmittance by external partitions, W/K

$H_{v e} \quad-$ thermal transmittance by ventilation, $\mathrm{W} / \mathrm{K}$

$I_{\text {sol }} \quad-$ solar irradiance, $\mathrm{W} / \mathrm{m}^{2}$

$R_{\text {tot }} \quad-$ total thermal resistance between the external and internal environment, $\mathrm{K} / \mathrm{W}$

$T_{e} \quad$ - external air temperature, $\mathrm{K}$

$T_{i} \quad-$ internal air temperature, $\mathrm{K}$

$T_{i, s e t, C}-$ set-point air temperature for cooling, $\mathrm{K}$

$T_{i, \text { set, },} \quad$ - set-point air temperature for heating, $\mathrm{K}$

\section{Greek letters}

$\tau \quad-$ thermal time constant, $\mathrm{s}$

$\phi_{c} \quad-$ heat flux to the thermal capacitance, W

$\phi_{e} \quad-$ heat flux through the external envelope, $\mathrm{W}$

$\phi_{g} \quad-$ total heat gains in the zone, $\mathrm{W}$

$\phi_{H C} \quad-$ heating or cooling power, W

$\phi_{H C, n d, a c}-$ actual heating or cooling power, $\mathrm{W}$

$\phi_{\text {int }} \quad-$ internal heat gains, W

$\phi_{\text {sol }} \quad-$ solar heat gains, W

\section{Subscript}

$n \quad-$ number of time step, -

\section{References}

1. Sikora M., Siwek K. (2018). Energy audit of the residential building. Journal of Mechanical and Energy Engineering, Vol. 2, No. 4, pp. 317-328 https://doi.org/10.30464/jmee.2018.2.4.317

2. Hunn B.D. (1996). Fundamentals of Building Energy Dynamics. MIT Press, Cambridge

3. P. Tuomaala, K. Saari. (1994). Selection and evaluation of a thermal simulation method for a building simulator. Helsinki University of Technology, Dept of Energy Engineering, Laboratory of Applied Thermodynamics, Report 78, Espoo

https://www.aivc.org/sites/default/files/airbase 8219.pdf

4. Kreith F., West R.E. (1997). CRC Handbook of Energy Efficiency, CRC Press, Bosa Roca, United States

5. Ghiaus C. (2013). Causality issue in the heat balance method for calculating the design heating and cooling load. Energy, Vol. 50, pp. 292-301 https://doi.org/10.1016/j.energy.2012.10.024

6. Kramer R., van Schijndel J., Schellen H. (2012) Simplified thermal and hygric building models: A literature review, Frontiers of Architectural Research. Vol. 1, Issue 4, pp. 318-325 https://doi.org/10.1016/j.foar.2012.09.001

7. Weismanová J. (2012). Dynamic thermal models in building simulations. In: 31. Setkání Kateder Mechaniky Tekutin A Termomechaniky, Mikulov. Proceedings. pp. 26-29. http://147.229.133.13/file/358?file=358\&lang=1

8. Hudson G., Underwood C.P. (1999). A simple building modelling procedure for Matlab/Simulink. In: Proceedings of Building Simulation '99, Kyoto, Japan. http://www.ibpsa.org/\%5Cproceedings\%5CBS1999\%5C BS99 PA-05.pdf

9. Węglarz A., Narowski P. (2011). The optimal thermal design of residential buildings using energy simulation and fuzzy sets theory. In: Proceedings of Building
Simulation 2011: 12th Conference of International Building Performance Simulation Association, Sydney. http://www.ibpsa.org/proceedings/BS2011/P_1277.pdf

10. Wilson M.B., Luck R., Mago P.J. (2015). A First-Order Study of Reduced Energy Consumption via Increased Thermal Capacitance with Thermal Storage Management in a Micro-Building. Energies, Vol. 8, No. 10, pp. 12266-12282. https://doi.org/10.3390/en81012266

11. Oliveira Panão M.J.N., Santos C.A.P., Mateus N.M., Carrilho da Graca G. (2016). Validation of a lumped RC model for thermal simulation of a double skin natural and mechanical ventilated test cell. Energy and Buildings, Vol. 121, pp. 92-103 http://dx.doi.org/10.1016/j.enbuild.2016.03.054

12. Kuniyoshi R., Kramer M., Lindauer M. (2018). Validation of RC Building Models for Applications in Energy and Demand Side Management. In: Proceedings of eSim 2018, the $10^{\text {th }}$ conference of IBPSA-Canada, Montréal, QC, Canada, May 9-10, 2018, pp. 133-142. http://www.ibpsa.org/proceedings/eSimPapers/2018/1-2B-4.pdf

13. Fuchs M., Teichmann J., Lauster M., Remmen P. Streblow R., Müller D. (2016). Workflow automation for combined modeling of buildings and district energy systems. Energy, Vol. 117, pp. 478-484 http://dx.doi.org/10.1016/j.energy.2016.04.023

14. Vivian J., Mazzi N. (2019). An algorithm for the optimal management of air-source heat pumps and PV systems. Journal of Physics: Conference Series, Vol. 1343, Art. No. 012069. doi:10.1088/1742-6596/1343/1/012069

15. Lauster M., Remmen P., Fuchs M., Teichmann J., Streblow R., Müller D. (2014). Modelling long-wave radiation heat exchange for thermal network building simulations at urban scale using Modelica. In: Proceedings of the 10th International Modelica Conference, March 10-12, 2014, Lund, Sweden, pp. 125133. doi: 10.3384/ECP14096125

16. PN-EN ISO 13790:2009 (2009): Energy performance of buildings. Calculation of energy use for space heating and cooling. The Polish Committee for Standardization

17. K.J. Kontoleon, D.K. Bikas. (2002). Modeling the influence of glazed openings percentage and type of glazing on the thermal zone behavior. Energy and Buildings, Vol. 34, pp. 389-399 https://doi.org/10.1016/ S0378-7788(01)00125-6

18. Lebrun J. (1989). Modelling of Thermal Systems from Technical Sketches to Equations. In: Proceedings of Building Simulation '89, Vancouver, British Columbia, Canada, June 23- 24, 1989, pp. 13-18

19. Desoer Ch.A., Kuh E.S. (1969). Basic Circuit Theory. McGraw-Hill Book Company, New York

20. Wang Y., Liu Y., Wang D., Liu J. (2014). Effect of the night ventilation rate on the indoor environment and airconditioning load while considering wall inner surface moisture transfer. Energy and Buildings, Vol. 80, pp. 366-374. http://dx.doi.org/10.1016/j.enbuild.2014.05.051

21. Landsman J., Brager G., Doctor-Pingel M. (2018). Performance, prediction, optimization, and user behavior of night ventilation. Energy and Buildings, Vol. 166, pp. 60-72. https://doi.org/10.1016/j.enbuild.2018.01.026

22. Anand P., Sekhar C., Cheong D., Santamouris M., Kondepudi S. (2019). Occupancy-based zone-level VAV system control implications on thermal comfort, ventilation, indoor air quality and building energy efficiency. Energy and Buildings, Vol. 204, Art. no. 109473. https://doi.org/10.1016/j.enbuild.2019.109473

23. Michalak P., Grygierczyk S. (2019). Temperature efficiency of heat exchangers in air handling units. Journal of Mechanical and Energy Engineering, Vol. 3 (43), No. 3, pp. 267-272. DOI: 10.30464/jmee.2019. 3.3.267 
24. Sonderegger R. (1978). Diagnostic Tests Determining the Thermal Response of a House. Lawrence Berkeley Laboratory. https://escholarship.org/uc/item/4x96z8c5

25. Bruno R., Brombach U., Steinmuller B. (1979). On Calculating Heating and Cooling Requirements. Energy and Buildings, Vol. 2, No. 3, pp. 197-202 https://doi.org/10.1016/0378-7788(79)90004-5

26. Braham W. (1981). Dynamic Indices of Building Thermal Performance. Departmental Papers (Architecture), Vol. 28, pp. 141-145 http://repository.upenn.edu/arch papers/28

27. Wortman D., O'Doherty B., Judkoff R. (1981). Implementation of an analytical verification technique on three building energy-analysis codes: SUNCAT 2.4, DOE 2.1, and DEROB III, Solar Energy Research Institute. https://www.nrel.gov/docs/legosti/old/1008.pdf

28. Nielsen A., Nielsen B.K. (1984). A Dynamic Test Method for the Thermal Performance of Small Houses: Model Set-up, Test Design, Measurements, Parameter Estimation and Simulation. In: Proceedings of American Council for an Energy-Efficient Economy Symposium, Santa Cruz, California, USA, August 1984 https://www.aceee.org/files/proceedings/1984/data/paper s/SS84 Panel2 Paper 17.pdf

29. Subbarao K., Burch J., Hancock E., Jeon H. (1985). Measurement of effective thermal capacitance in buildings. In: Proceedings ASHRAE/DOE/BTECC Conference on Thermal Performance of the Exterior Envelope of Buildings, Clearwater Beach, Florida, USA. https:/web.ornl.gov/sci/buildings/conf-archive/1985\%20 B3 \%20papers/026.pdf

30. Van Der Maas J., Maldonado E. (1997). A new thermal inertia model based on effusivity. International Journal of Sustainable Energy, Vol. 19, No. 1, pp. 131-160. http://dx.doi.org/10.1080/01425919708914334

31. Sirén K., Hasan A. (2007). Comparison of two calculation methods used to estimate cooling energy demand and indoor summer temperatures. In: Clima 2007 WellBeing Indoors, 10-14 June, Finland, Helsinki. https://www.irbnet.de/daten/iconda/CIB7990.pdf

32. Kopecký P. (2011). Two Simplified Thermal Models of the Ventilated Zone. In: Tywoniak, J. (edt.) Sustainable constuction of buildings - Udržitelná výstavba budov. Praha, pp. 39-44

33. Široký J., Oldewurtel F., Cigler J., Prívara S. (2011) Experimental analysis of model predictive control for an energy efficient building heating system. Applied Energy, Vol. 88, pp. 3079-3087 doi:10.1016/j.apenergy. 2011.03.009

34. Missaoui R., Joumaa H., Ploix S., Bach S. (2014) Managing energy Smart Homes according to energy prices: Analysis of a Building Energy Management System. Energy and Buildings, Vol. 71, pp. 155-167. http://dx.doi.org/10.1016/j.enbuild.2013.12.018

35. Wilson M.B., Luck R., Mago P.J. (2015). A First-Order Study of Reduced Energy Consumption via Increased Thermal Capacitance with Thermal Storage Management in a Micro-Building. Energies, Vol. 8, pp. 12266-12282. doi:10.3390/en81012266

36. Vivian J., Zarrella A., Emmi G., De Carli M. (2017). An evaluation of the suitability of lumped-capacitance models in calculating energy needs and thermal behaviour of buildings. Energy and Buildings, Vol. 150, pp. 447-465

http://dx.doi.org/10.1016/j.enbuild.2017.06.021

37. Kopecký P., Staněk K. (2014). Estimating the input parameters of lumped building thermal models on the basis of standard design values. In: NSB 2014, 10th Nordic Symposium on Building Physics, 15-19 June 2014 Lund, Sweden, Full papers - NSB 2014, pp. 742-749
38. Kopecký P., Staněk K. (2018). Review of Three WhiteBox Lumped Parameter Building Thermal Models. Heating, Ventilation, Sanitation, Vol. 6/2018, pp. 348355. http://www.stpcr.cz/en/issue-2018-6

39. Wit de M.H., Driessen H.H., Velden van der R.M.M. (1987). ELAN: a computer model for building energy design: theory and validation. Technische Universiteit Eindhoven

40. Ashouri A., Fazlollahi S., Benz M.J., Maréchal F. (2015). Particle Swarm Optimization and Kalman Filtering for Demand Prediction of Commercial Buildings. In: Proceedings of ECOS 2015 - The 28th International Conference on Efficiency, Cost, Optimization, Simulation and Environmental Impact of Energy Systems, June 30-July 3, 2015, Pau, France

41. Park H., Ruellan M., Bouvet A., Monmasson E., Bennacer R. (2011). Thermal parameter identification of simplified building model with electric appliance. In: Proceedings of the 11th international conference on electrical power quality and utilisation (EPQU). Vol. no. 17-19. DOI: 10.1109/EPQU.2011.6128822

42. Ramallo-González A.P., Brown M., Coley D.A. (2015). Identifying the ideal topology of simple models to represent dwellings. In: Proceedings of BS2015: 14th Conference of International Building Performance Simulation Association, Hyderabad, India, Dec. 7-9, 2015, pp. 688-695 http://www.ibpsa.org/proceedings/BS2015/p2432.pdf

43. Harb H., Boyanov N., Hernandez L., Streblow R., Müller D. (2016). Development and validation of grey-box models for forecasting the thermal response of occupied buildings. Energy and Buildings, Vol. 117, pp. 199-207. http://dx.doi.org/10.1016/j.enbuild.2016.02.021

44. PN-EN 28601:2002 (2002): Data elements and interchange formats - Information interchange Representation of dates and times. The Polish Committee for Standardization

45. Narowski P., Janicki M., Heim D. (2013). Comparison of untypical meteorological years (UMY) and their influence on building energy performance simulations. In: Proceedings of BS2013: 13th Conference of International Building Performance Simulation Association, Chambéry, France, August 26-28. http://www.ibpsa.org/proceedings/BS2013/p_1466.pdf

46. Kulesza K. (2017). Comparison of typical meteorological year and multi-year time series of solar conditions for Belsk, central Poland. Renewable Energy, Vol. 113, pp. 1135-1140 https://doi.org/10.1016/ j.renene.2017.06.087

47. Rudniak J. (2019). Solar parameters of the local climate during the summer in relation to data from typical meteorological year. E3S Web Conf. Vol. 116 Art. no. 00066. https://doi.org/10.1051/e3sconf/201911600066

48. Loutzenhiser P., Manz H., Maxwell G. (2007). Empirical Validations of Shading/Daylighting/Load Interactions in Building Energy Simulation Tools. A Report for the International Energy Agency's SHC Task 34. http://www.equaonline.com/iceuser/validation/IEATask3 4.pdf

49. Zhu D., Yan D., Wang C, Hong T. (2012). Comparison of Building Energy Modeling Programs: Building Loads. LBNL Report E, vol. 6034 https://www.osti.gov/ servlets/purl/1168735

50. Venkateshan S.P., Swaminathan P. (2014). Computational Methods in Engineering. Academic Press https://doi.org/10.1016/B978-0-12-416702-5.50008-9

51. Jayanti S. (2018). Computational Fluid Dynamics for Engineers and Scientists. Springer, Dordrecht. https://doi.org/10.1007/978-94-024-1217-8 
52. Curnier A. (1994). Computational Methods in Solid Mechanics. Springer Science+Business Media, Dordrecht https://doi.org/10.1007/978-94-011-1112-6

53. Hundsdorfer W., Verwer J. (2003). Numerical Solution of Time-Dependent Advection-Diffusion-Reaction Equations. Springer-Verlag Berlin Heidelberg https://doi.org/10. 1007/978-3-662-09017-6

54. Ooi A. (2005). Advanced Computational Mechanics. Lecture notes. The University of Melbourne. https://people.eng.unimelb.edu.au/asho/AdvCompMech/ notes.pdf

55. Vande Wouwer A., Saucez P., Vilas C. (2014). Simulation of ODE/PDE Models with MATLAB ${ }^{\circledR}$, OCTAVE and SCILAB. Springer International Publishing, Cham https://doi.org/10.1007/978-3-319-06790-2

56. Skre Fjordholm U. (2018). Numerical methods for ordinary differential equations. Lecture notes. University of Oslo

https://www.uio.no/studier/emner/matnat/math/MAT344 0/v18/pensumliste/numerical methods.pdf

57. Neymark J., Judkoff R., Knābe G., Le H.T., Dürig M., Glass A., Zweifel G. (2002). Applying the building energy simulation test (BESTEST) diagnostic method to verification of space conditioning equipment models used in whole-building energy simulation programs. Energy and Buildings, Vol. 34, No. 9, pp. 917-93. https://doi.org/10.1016/S0378-7788(02)00072-5

58. ANSI/ASHRAE, Standard 140-2017 (2017): Standard Method of Test for the Evaluation of Building Energy Analysis Computer Programs. American National Standards Institute

59. Narowski P., Mijakowski M., Panek A., Rucińska J., Sowa J. (2010). Proposal of simplified calculation 6R1C method of buildings energy performance adopted to Polish conditions. In: Central Europe towards Sustainable Building Energy Efficiency, CESB10 Prague. http://www.irbnet.de/daten/iconda/CIB17831.pdf

60. Narowski P., Mijakowski M., Panek A., Rucińska J., Sowa J. (2010). Integrated 6R1C energy simulation method - principles, verification and application. In: CLIMA 2010, 11th REHVA World Congress "Sustainable Energy Use in Buildings", Antalya, Turkey

61. Gajewski R., Pieniążek P. (2017). Building energy modelling and simulations: qualitative and quantitative analysis. In: MATEC Web Conf., Vol. 117, Art. no. 00051 DOI: $10.1051 /$ matecconf $/ 201711700051$

62. Gajewski R.R., Kułakowski T. (2018). Towards Optimal Design of Energy Efficient Buildings. Archives of Civil Engineering, Vol. 64: No. 4, pp. 135-153. https://doi.org/ 10.2478/ace-2018-0067

63. Henninger R.H., Witte M.J. (2004). EnergyPlus Testing with ANSI/ASHRAE Standard 140-2001 (BESTEST) EnergyPlus Version 1.2.0.029. Ernest Orlando Lawrence Berkeley National Laboratory Berkeley, California. https://simulationresearch.lbl.gov/dirpubs/epl_bestest_as h.pdf

64. PN-EN ISO 13786:2007 (2007): Thermal performance of building components - Dynamic thermal characteristics - Calculation methods. The Polish Committee for Standardization

65. Michalak P. (2019). Modelling of global solar irradiance on sloped surfaces in climatic conditions of Kraków. New Trends in Production Engineering, Vol. 2, No. 1, pp. $505-514$ doi: https://doi.org/10.2478/ntpe-2019-0054

66. Jedrzejuk H., Rucińska J. (2015). Verifying a need of artificial cooling - a simplified method dedicated to single-family houses in Poland. Energy Procedia, Vol. 78, pp. 1093-1098. doi: 10.1016/j.egypro.2015.11.061
67. Capizzi G., Lo Sciuto G., Cammarata G., Cammarata M. (2017). Thermal transients simulations of a building by a dynamic model based on thermal-electrical analogy: Evaluation and implementation issue. Applied Energy, Vol. 199, pp. 323-334 http://dx.doi.org/10.1016/ j.apenergy.2017.05.052

68. Costantino A., Fabrizio E., Ghiggini A., Bariani M. (2018). Climate control in broiler houses: A thermal model for the calculation of the energy use and indoor environmental conditions. Energy and Buildings, Vol. 169 , pp. 110-126 https://doi.org/10.1016/j.enbuild. 2018.03.056

69. Elci M., Delgado B.M., Henning H.M., Henze G.P., Herkel S. (2018). Aggregation of residential buildings for thermal building simulations on an urban district scale. Sustainable Cities and Societies, Vol. 39, pp. 537-547 https://doi.org/10.1016/j.scs.2018.03.015

70. Horvat I., Dović D. (2016). Dynamic modeling approach for determining buildings technical system energy performance, Energy Conversion and Management, Vol. 125, pp. 154-165. http://dx.doi.org/10.1016/j.enconman. 2016.03 .062

\section{Biographical note}

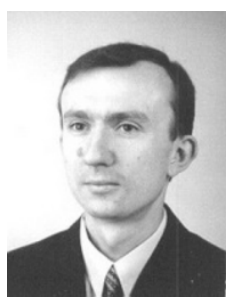

Piotr Michalak received Ph.D degree in Energy Machines and Equipment from AGH, Kraków. Since 2009 he has been a researcher in the Department of Power Systems and Environmental Protection Facilities at the AGH. His scientific interests focus on problems concerning energy modelling and thermal dynamics of buildings, utilisation of renewable energy sources, CFD simulations and thermal and flow measurements. He is the author or coauthor of 62 scientific papers. 